\title{
IMPACT OF SINGLE BOUT OF PHYSICAL EXERCISE ON ADOLESCENTS' STRENGTH AND BALANCE ABILITIES
}

\author{
Lina Kreivẻnaitė, Vytautas Streckis, Sandra Raizgytė, Asta Lileikienė \\ Lithuanian Sports University, Kaunas, Lithuania
}

\begin{abstract}
Background. There is evidence of physical exercise effect on the adolescents' balance and strength; however it is not known how aforementioned variables respond to physical exercise with different loads and intensities. Therefore, the aim of the study was to assess the impact of single bout of physical exercise of different intensity on adolescents' body balance and muscular strength.

Methods. Thirty healthy, physically active 11-13-year-old adolescents were randomly allocated to one of the two groups. Both groups performed single bout of physical exercise of high- or low-intensity climbing up and downstairs. Postural sway and maximum voluntary contractions (MVC) were assessed before and after physical exercise.

Results. No statistically significant impact of low or high intensity exercise was found at adolescents' MVC. High intensity exercise influenced bigger postural sway with eyes closed compared to eyes open $(p<.05)$. After high-intensity exercise there was a significantly greater postural sway with eyes closed than with eyes open $(p<.05)$.

Conclusions. High and low intensity physical exercise had no impact on the adolescents' maximum voluntary contraction, whereas high intensity exercise deteriorated body balance with eyes closed.
\end{abstract}

Keywords: adolescence, physical exercise, MVC, balance.

\section{INTRODUCTION}

$\mathrm{I}$ is widely accepted that there is the direct benefit of regular physical activity on health (Bouchard \& Rankinen, 2001; Doherty, 2003; Fitts, 2003). Lack of physical activity can lead to cardiovascular system disorders, obesity, diabetes and manifestations of other diseases (US Department of Health and Human Services, 1996). Insufficient physical activity is closely associated with the choice of a sedentary lifestyle in future as well (Malina, 2001; Telama et al., 2005), which can be responsible for the quickly resulting fatigue and may increase the risk of diseases related with low levels of physical activity as well as advance the manifestation of age-related diseases (US Department of Health and Human Services, 1996). There is much evidence that the family and environmental impact is a significant factor in choosing the level of physical activity (Bouchard
\& Rankinen, 2001). Moreover, the results of some studies have shown that participation in organized sport in childhood and adolescence is a good predictor of physical activity in adulthood (Barnekow-Bergkvist, Hedberg, Janlert, \& Jansson, 1998; Engström, 1991; Malina, 2001; Tammelin, Näyhä, Hills, \& Järvelin, 2003; Telama, Yang, Laakso, \& Viikari, 1997). Significant reduction in human physical activity has been considered by many authors (Bouchard \& Rankinen, 2001; Doherty, 2003; Fitts, 2003; Telama et al., 2005; Westerståhl, Barnekow-Bergkvist, \& Jansson, 2005). It is also noted that more people are engaged in a monotonous manual activity at work, requiring repetitive muscle contractions or prolonged maintenance of unusual posture (Latash, 2008). Such activity increases local muscle fatigue and even the risk of injuries (Skurvydas, Brazaitis, Kamandulis, 
\& Sipaviciene, 2010; M. H. Stone, M. Stone, \& Sands, 2007). In addition, adolescents also spend more time in activities with low level of dynamic movement (US Department of Health and Human Services, 1996; Bouchard \& Rankinen, 2001; Doherty, 2003). It is not completely clear yet what effect age has on fatigue. Children often show a lower level of fatigue than adults (Kanehisa, Yata, Ikegawa, \& Fukunaga, 1995; Streckis, Skurvydas, $\&$ Ratkevicius, 2007). Most fatigue tests are based on muscle strength or capacity measurements while performing high-intensity exercises. An ability to activate skeletal muscles can be of great importance to fatigue during this kind of exercises (Gandevia, 2001; Streckis et al., 2007; Skurvydas, Brazaitis, Venckunas, \& Kamandulis, 2011a). The research investigation discovered that voluntary activation results of adolescents are controversial, additionally, it is known that adolescents show different response to central fatigue compared to adults (Blimkie, Sale, \& Bar-Or, 1990; Stackhouse, Binder-Macleod, \& Lee, 2005; Streckis et al., 2007; Skurvydas et al., 2011b). For these reasons, the problem remains relevant in the international scientific literature about human physical fatigue, otherwise known as muscle fatigue. Although the world literature studies target to establish guidelines for health and adequate physical loads for children and adolescents, these studies have limiting factors due to different methodologies (Brener et al., 2004; Department of Health, 1997; Gregory et al., 2000; Grunbaum et al., 2004). Moreover, what nature, intensity and duration of physical exercise are sufficient for adolescents to ensure the adequate development of their body and good health, and what exercise may result in the occurrence of fatigue has not been determined yet. On the basis of the above-mentioned findings we set the aim of the study - to assess the impact of single bout of physical exercising of different intensity on adolescents' body balance and muscular strength.

\section{METHODS}

Research sample. Thirty healthy and physically active adolescents voluntarily agreed to participate in our study. The age of research sample was between 11 and 13 years. The study included 14 boys (height $171.6 \pm 6.2 \mathrm{~cm}$, weight $59.2 \pm$ $4.3 \mathrm{~kg}$ ) and 16 girls (height $169.0 \pm 6.6 \mathrm{~cm}$, weight $50.6 \pm 6.4 \mathrm{~kg}$ ). The participating adolescents were physically active and attended physical education lessons twice a week.
Body Balance. For the assessment of the research subjects' balance, the tenzoplatform "KISTLER" and computer equipment for signal records were used (Cesnaitiene et al., 2010). Balance was recorded during quiet stance of $30 \mathrm{~s}$ with eyes open, looking straight to the selected point at the eye level at a 2-meter distance, arms at sides. After that, the same procedure was performed with eyes closed. Balance assessment tests of the research participants were carried out before and after physical exercise.

Assessment of Maximal Voluntary Contraction (MVC). The maximum voluntary contraction (MVC) of quadriceps femoris was assessed using the Biodex isokinetic dynamometer performing two repetitions of $3 \mathrm{~s}$, with a two-minute rest between them. Lower limb bending angle was $120^{\circ}$.

Measuring of heart rate. During exercise, the pulse frequency of the subjects was strictly controlled using the "Polar RS800CX" heart rate monitor. Heart rate (HR) limits of each participant were determined individually and not exceeded during the physical exercise.

Physical Exercise. The research subjects were divided into two groups. The first group of the subjects performed a high-intensity continuous 30 min exercise. Heart rate (HR) was over $70 \%$ (no less than 150 beats/min) of maximum individual pulse rate. The second group of the subjects performed a low-intensity 30-minute exercise. Their HR did not exceed $70 \%$ (up to 150 beats $/ \mathrm{min}$ ) of the maximum heart rate of an individual. The single bout of physical exercising was carried out by climbing up and going downstairs continuously. The subjects were strictly monitored; each had to climb the stairs meeting HR standards.

Experimental protocol. The measurements were carried out at the same time of day. The anthropometric measurements were performed at the beginning of the research. Later, balance test, using the Kistler's tenzoplatform, was carried out. After the warm up with the veloergometer (20$30 \mathrm{~W}$ power for 10 minutes, HR -120 to 145 beats/ $\mathrm{min}$ ), the maximum voluntary contraction (MVC) was estimated using the dynamometer. After the initial measurements, the physical exercises of the required duration and intensity were carried out (see section "physical exercise"). After the exercise, when the HR recovered to the resting level, the balance and MVC tests of the subjects were performed repeatedly.

Analysis of Statistical Data. Data analysis was performed using the Statistical Package for Social 
Sciences (SPSS), program 17 version. The study data was processed determining the arithmetic means of the research group $(x)$, the dispersion was evaluated in association with standard deviations $(S)$. The significance of the group mean differences $(p)$ was evaluated using the Student $(t)$ criterion. The differences between the means were considered statistically significant when $p<.05$.

\section{RESULTS}

Dynamics of MVC. Prior to the high-intensity physical exercise, it was found that the MVC of girls was $160.7 \pm 50.8 \mathrm{~N} \cdot \mathrm{m}$. After the MVC test the girls performed the high-intensity continuous $30 \mathrm{~min}$ exercise. The exercise intensity was 70 $89 \%$ of the individual maximal heart rate (HR). The analysis of heart rate indicators showed that the girls' average HR was $169.6 \pm 10.2$ beats $/ \mathrm{min}$. It was also found that the girls climbed stairs (up and down) $13.9 \pm 1.9$ times on average, and one risedescent took an average of $2.15 \pm 0.45 \mathrm{~min}$. After the exercise the subjects performed MVC test repeatedly. It was discovered that after the highintensity exercise the girls' MVC slightly increased to $169.1 \pm 50.9 \mathrm{~N} \cdot \mathrm{m}$, but no statistically significant difference was observed $(p>.05)$.

The analysis of 11 to 13 -year-old girls' MVC test results before the low-intensity physical activity determined that the girls' MVC was $171.1 \pm 47.9 \mathrm{~N} \cdot \mathrm{m}$. After the MVC test the girls performed the continuous $30 \mathrm{~min}$ exercise of lowintensity. The exercise intensity was not more than $70 \%$ of the individual maximal heart rate.
The analysis of HR indicators showed that girls' average HR was $146.3 \pm 9.5$ beats $/ \mathrm{min}$. It was also identified that during exercise the girls climbed the stairs (up-down) $7.5 \pm 2.2$ times on average. One rise-descent took an average of $4.09 \pm 0.35 \mathrm{~min}$. After the low-intensity continuous exercise the subjects' MVC test was re-done. The evaluation of MVC test results of the participants after the exercise demonstrated no statistically significant change in the force $172.9 \pm 49.9 \mathrm{~N} \cdot \mathrm{m}$ (Figure 1).

The analysis of 11-13- year-old boys' MVC test results prior to the high-intensity exercise showed that the boys' MVC was $238.9 \pm 47.5 \mathrm{~N} \cdot \mathrm{m}$. After the MVC test performance the boys performed the high-intensity continuous $30 \mathrm{~min}$ exercise. The exercise intensity was $70-89 \%$ of the individual maximal heart rate. The analysis of HR indicators showed that the boys mean HR after the highintensity exercise was $165.9 \pm 11.4$ beats $/ \mathrm{min}$. It was also found that the boys climbed the stairs up and down an average of $14.3 \pm 2.1$ times during the 30 min exercise. One rise-descent took an average of $2.09 \pm 0.37 \mathrm{~min}$. After the intense continuous exercise the subjects' MVC test was re-done. It was identified that after exercise the boys' MVC rose to $239.6 \pm 49.8 \mathrm{~N} \cdot \mathrm{m}$, with no statistically significant difference between the loads.

Before carrying out the low-intensity physical exercise, it was found that boys' MVC was $247.4 \pm$ $50.1 \mathrm{~N} \cdot \mathrm{m}$. After the MVC test the boys performed the continuous $30 \mathrm{~min}$ exercise of low-intensity. The exercise intensity was not more than $70 \%$ of the individual maximal heart rate. The analysis of HR indicators showed that the boys' average HR

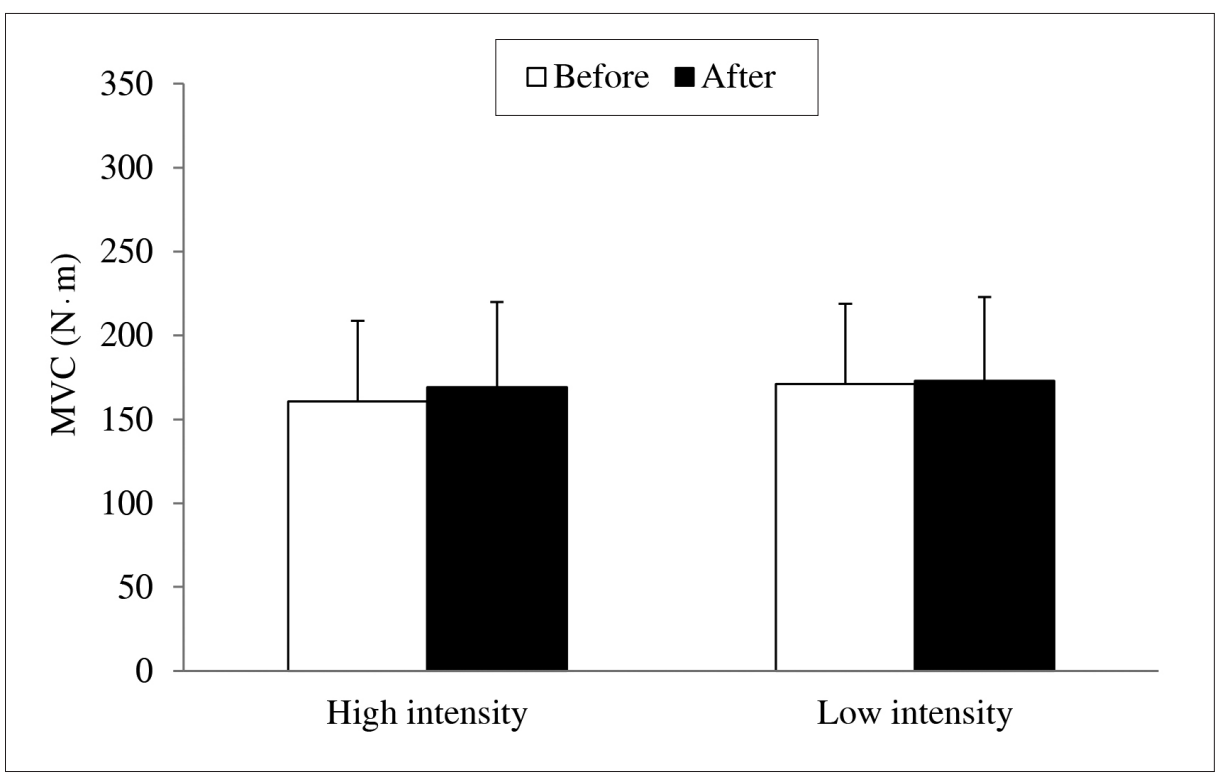

Figure 1. Girls' MVC test results before and after high and low intensity exercise 
was $143.4 \pm 9.8$ beats/min during the low-intensity exercise. It was also discovered that during exercise the boys climbed the stairs up and down an average of $7.9 \pm 1.9$ times, and a rise-descent took an average of $3.8 \pm 0.29 \mathrm{~min}$. After the exercise the MVC test was re-done. The evaluation of the MVC of the subjects after the low-intensity exercise showed that the force did not change statistically significantly $-255.9 \pm 50.2 \mathrm{~N} \cdot \mathrm{m}$ (Figure 2 ).

Dynamics of balance abilities. The body balance test was performed while the subjects were standing on both legs for $30 \mathrm{~s}$ with eyes open and $30 \mathrm{~s}$ with eyes closed before and immediately after the performed exercise. Eyes open and eyes closed test results were compared with the results before and after the exercise, the difference between the postural body sway with eyes open and eyes closed was also examined. The research results are presented in the graphs (Figure 3, Figure 4) below.

After analysing the girls' body balance results before and after the low-intensity exercise it was found that the postural sway with eyes open before the exercise was equal to $0.81 \pm 0.29 \mathrm{~mm} / \mathrm{s}$, and after exercise it was $1.35 \pm 0.42 \mathrm{~mm} / \mathrm{s}$. During the test with closed eyes the girls' postural sway before the exercise was $1.3 \pm 0.55 \mathrm{~mm} / \mathrm{s}$ and after the exercise the result changed to $1.38 \pm 0.56 \mathrm{~mm} / \mathrm{s}$. However, these variations were not statistically significant (Figure 3). Comparing the girls' postural sway difference between the test with eyes open
Figure 2. Boys' MVC test results before and after high and low intensity exercise
Figure 3. Girls' body balance test results with eyes open and eyes closed before and after low-intensity exercise
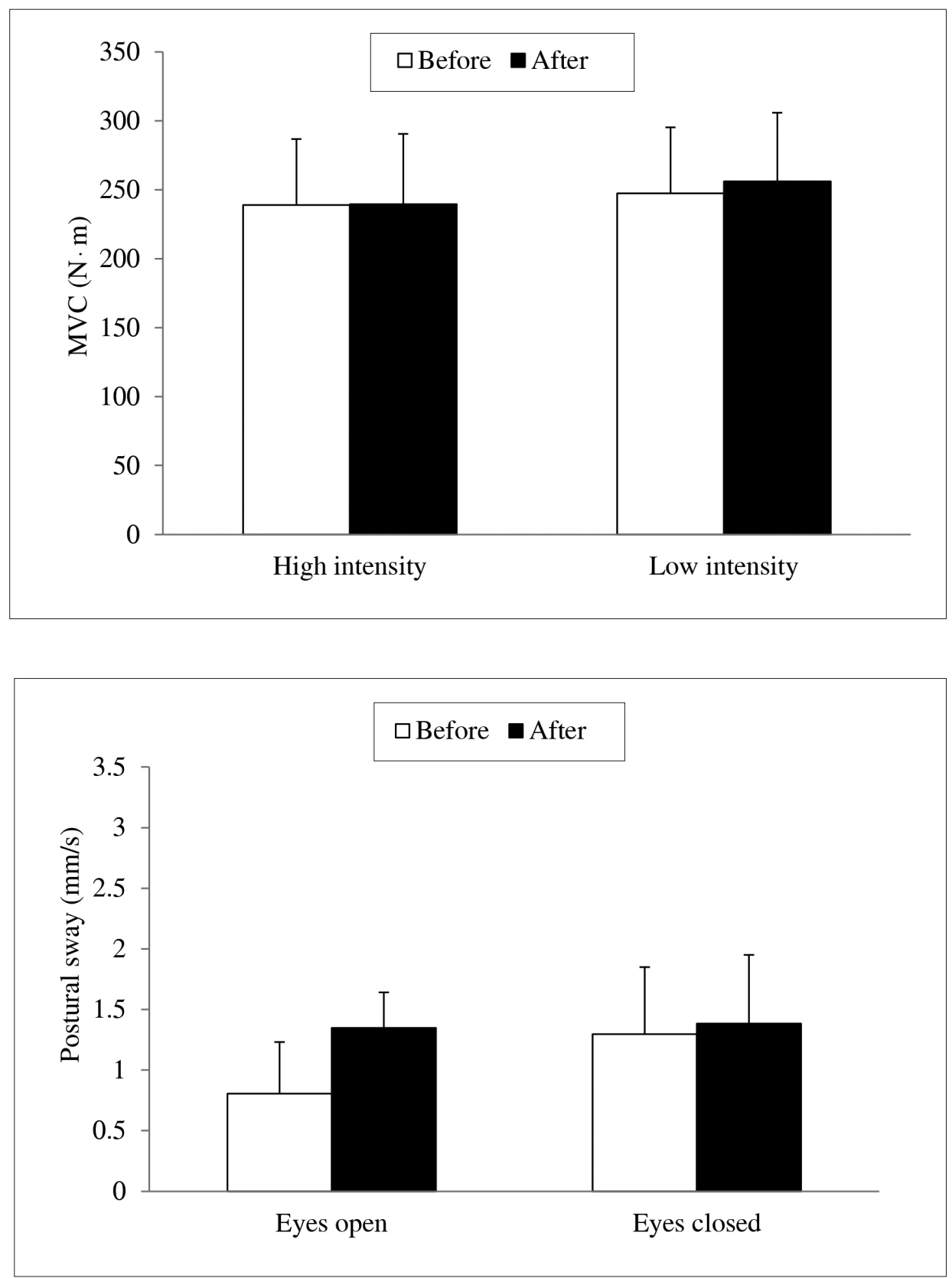
and with eyes closed it was determined that before the low-intensity physical exercise the difference between these tests was equal to $0.53 \mathrm{~mm} / \mathrm{s}$. After the exercise, the difference between the eyes open test and eyes closed test changed to $0.09 \mathrm{~mm} / \mathrm{s}$, but it is not statistically significant as well.

The analysis of the girls' body balance test results before and after the high-intensity physical exercise showed that the postural sway with eyes open changed from $1.02 \pm 0.35$ to $1.19 \pm$ $0.43 \mathrm{~mm} / \mathrm{s}$. Meanwhile, the girls' postural sway with eyes closed after the high-intensity exercise significantly increased from $1.29 \pm 0.65$ to $2.75 \pm$ $0.58 \mathrm{~mm} / \mathrm{s}(p<.05)$. The comparison of the girls' body balance test results with eyes open and eyes closed showed that prior to the high-intensity physical activity the difference between the girls' postural sway with eyes open and eyes closed was only $0.17 \mathrm{~mm} / \mathrm{s}$ (Figure 4). However, after the highintensity exercise a significantly higher postural sway was identified $-1.46 \mathrm{~mm} / \mathrm{s}$ performing the eyes closed test $(p<.05)$.

The analysis of the boys' body balance test results before and after low-intensity exercise showed that the postural sway with eyes open was equal to $1.05 \pm 0.57 \mathrm{~mm} / \mathrm{s}$ before the load, and after the exercise the fluctuation changed to $1.64 \pm$ $0.59 \mathrm{~mm} / \mathrm{s}$. Meanwhile, the boys' postural sway with eyes closed before the load was $1.42 \pm 0.65 \mathrm{~mm} / \mathrm{s}$ and after the physical exercise the result altered
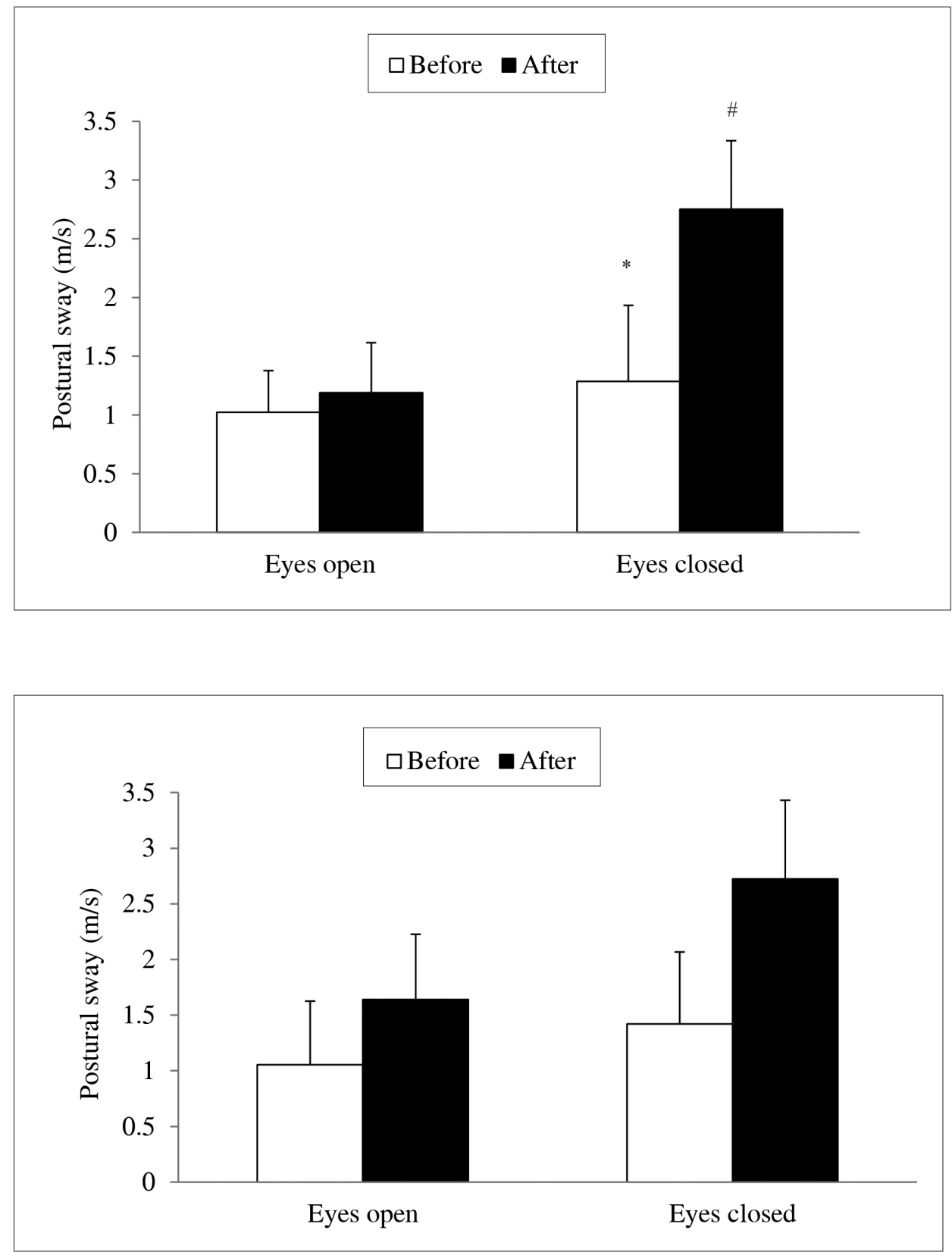

Figure 4. Girls' body balance test results with eyes open and eyes closed before and after high-intensity exercise

Note. $*-p<.05$, comparing tests before and after exercise; $\#-p<.05$, comparing eyes open and eyes closed tests.

Figure 5. Boys' body balance test results with eyes open and eyes closed before and after low-intensity exercise 
Figure 6. Boys' body balance test results with eyes open and eyes closed before and after highintensity exercise
Note. ${ }^{*}-p<.05$, comparing tests before and after exercise; $\#-p<.05$, comparing eyes open and eyes closed tests.

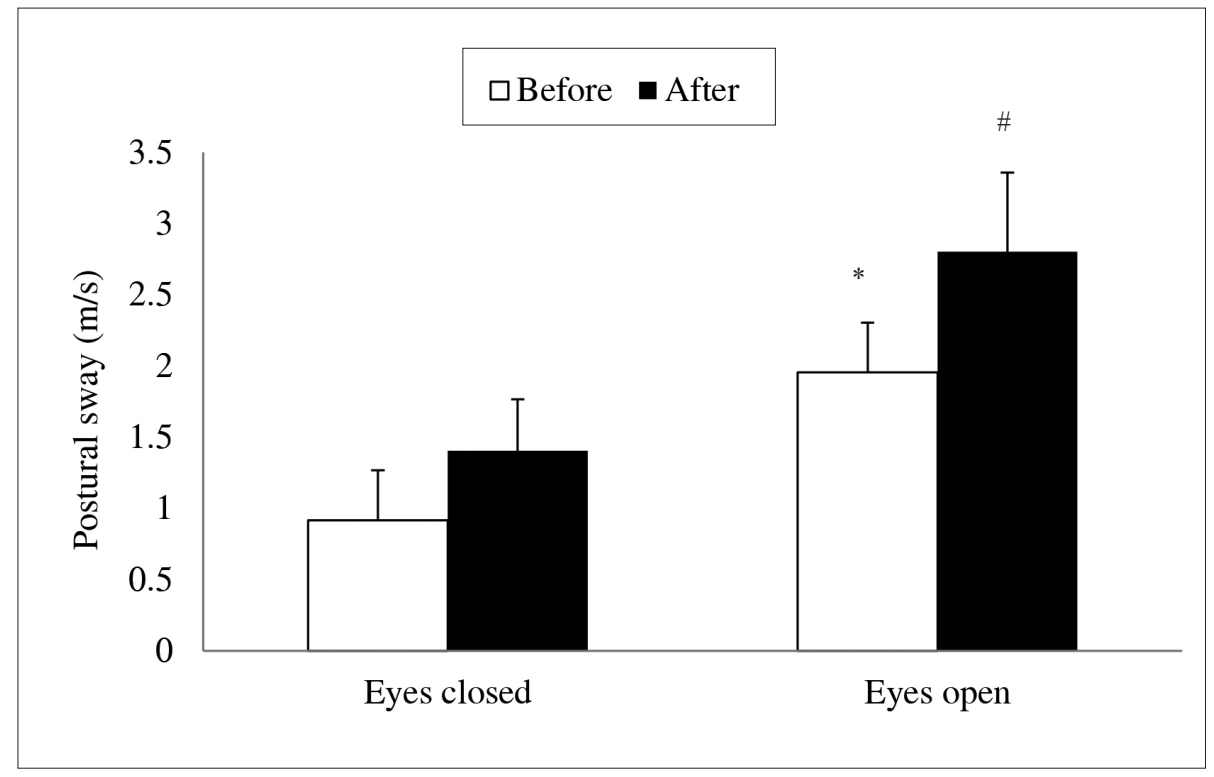

to $2.72 \pm 0.70 \mathrm{~mm} / \mathrm{s}$. However, these variations were not statistically significant. Comparing the difference between the boys' postural sway test with eyes open and eyes closed provides that before a low intensity physical exercise the difference between these tests was equal to $0.37 \mathrm{~mm} / \mathrm{s}$. After the exercise, the difference between eyes open and eyes closed tests increased to $1.08 \mathrm{~mm} / \mathrm{s}$, but this is not statistically reliable as well (Figure 5).

Comparing the boys' body balance before and after high-intensity physical exercise (Figure 6) it was determined that the postural sway with eyes open did not change significantly from $0.92 \pm$ 0.49 to $1.40 \pm 0.36 \mathrm{~mm} / \mathrm{s}$. Meanwhile, the boys' postural sway with eyes closed after high-intensity exercise increased statistically significantly from $1.95 \pm 0.56$ to $2.80 \pm 0.61 \mathrm{~mm} / \mathrm{s},(p<.05)$. The comparison of the body balance test results with eyes open and eyes closed showed that prior to high-intensity exercise the postural sway with eyes closed was $1.04 \mathrm{~mm} / \mathrm{s}$, significantly higher than in the eyes open test $(p<.05)$. Moreover, after highintensity exercise, the girls alike, and a significantly higher postural sway in the eyes closed test was determined $-0.68 \mathrm{~mm} / \mathrm{s},(p<.05)$.

\section{DISCUSSION}

Our research aim was to investigate the impact of one-time continuous physical exercise of different intensity on adolescents' body balance and force. The main finding of this study was that one-time low and high intensity continuous 30-minute physical exercise had no impact to the adolescents' maximum voluntary contraction, but it influenced their body balance with eyes closed.

Jansen and LeBlanc (2010) argue that the benefits of physical activity in adolescents' health can be achieved by actively moving 30 minutes a day on average. However, according to the recommendations of the World Health Organization (WHO) (2010) children and adolescents should be physically active for at least 60 minutes a day. The activity rate for children and adolescents can be achieved by accumulating and summing the different duration and type of physical activities. Even so, physical activity is recommended in no shorter than 5-minute intervals, but high-intensity physical exercise may be too strenuous for less active children and adolescents (Jansen \& LeBlanc, 2010).

As we have noted above, there is a relevant problem of significant reduction in human physical activity (Bouchard \& Rankinen, 2001; Doherty, 2003; Fitts, 2003; Telama et al., 2005; Westerståhl et al., 2005), which leads to large decreases in muscle mass and strength, as well as increased fatigability due to changes in muscle metabolism (Bloomfield, 1997; Rimmer, Schiller, \& Chen, 2012). For this reason, we expected that the exercise intensity and duration would cause motor system fatigue which will lead to a fall in MVC and increased body sway. As the adolescents' MVC did not change after low-intensity exercise, we can assume that the low-intensity exercise assigned to the subjects was insufficient in its duration and intensity to affect their MVC. It would be informative to examine the adolescents' MVC after the longer-term continuous low-intensity physical load to assess the appearance of motor fatigue. 
Nevertheless, the high-intensity physical activity did not affect the MVC results of adolescents either. Although Baker, Kostov, Miller, and Weiner (1993) state that the 15- to 20-minute exercise with intervals results in the adults' MVC reduction and slow force recovery, we can assume that 30 minutes of high-intensity physical activity was not sufficient to induce a decrease of MVC in physically active adolescents. It is also likely that fatigue could occur after a while, as the eccentric exercise can delay muscle pain, fibre injuries and reduce muscular functional capacities (Clarkson \& Hubal, 2002; Streckis, Skurvydas, \& Ratkevicius, 2005; Streckis et al., 2007). According to the WHO recommendations, the high-intensity physical activity for children and adolescents should not exceed 30 minutes per day, for this reason we could not evaluate the MVC after the longer-term continuous high-intensity physical load.

The result analysis after low-intensity exercise, the body balance results of adolescents with open and closed eyes remained unchanged in comparison with the testing carried out before the load. We believe that low-intensity 30-minute physical activity was insufficient to impact the amplitude of postural sway as well as the MVC of physically active adolescents. It is known that lower extremities are commonly used for locomotion and posture control - tasks that do not normally require fast contractions (Hirschfeld, 2007). There is no occurrence of motor fatigue testing the adolescents' MVC variations after low and high-intensity exercise, so absence of body balance alterations is not surprising.

However, the question remains why increased adolescents' postural sway in test with closed eyes after high-intensity physical load. While the body balance with eyes open after the 30-minute highintensity exercise did not change, but an increased postural sway was observed during the test with eyes closed. Similar results were recorded by other scientists (Cesnaitienė et al., 2010; Skurvydas et al., 2010). Katayama et al., (2004) found that the lack of visual information while standing with both legs together leads to the 1.5-time increase in the amplitude of sway. Diener, Dichgans, Bruzek, and Selinka (1982) also discovered that vision was an important factor in the most effective stabilization of balance. The increased postural sway after highintensity exercise can be influenced by the onset of motor system fatigue (Cesnaitienè et al., 2010; Skurvydas et al., 2010), decreased concentration and increased muscle activation (Streckis et al., 2005; Streckis et al., 2007). Moreover, there is a possibility that high-intensity physical activity affected the ear vestibular apparatus, which changed the balance results with eyes closed (Skurvydas et al., 2010).

\section{CONCLUSIONS}

Acute effect to continuous exercising of low or high intensities did not affect the muscular strength of adolescents but deteriorated their body balance. The greater effect on balance was found out while performing the balance task with closed eyes.

\section{REFERENCES}

Baker, A. J., Kostov, K. G., Miller, R. G., \& Weiner, M. W. (1993). Slow force recovery after long duration exercise: Metabolic and activation factors in muscle fatigue. Journal of Applied Physiology, 74, 2294-2300.

Barnekow-Bergkvist, M., Hedberg, G., Janlert, U., \& Jansson, E. (1998). Prediction of physical fitness and physical activity level in adulthood by physical performance and physical activity in adolescence an 18-year follow-up study. Scandinavian Journal of Medicine \& Science in Sports, 8, 299-308. doi: 10.1111/ j.1600-0838.1998.tb00486.x

Blimkie, C. J., Sale, D. G. \& Bar-Or, O. (1990). Voluntary strength, evoked twitch contractile properties and motor unit activation of knee extensors in obese and non-obese adolescent males. European Journal of Applied Physiology and Occupational Physiology, 61, 313-318. doi: 10.1007/BF00357619

Bloomfield, S. A. (1997). Changes in musculoskeletal structure and function with prolonged bed rest. Medicine and Science in Sports and Exercise, 29, 197-206. doi:10.1097/00005768-199702000-00006

Bouchard, C., \& Rankinen, T. (2001). Individual differences in response to regular physical activity. Medicine and Science in Sports and Exercise, 33, 446-451.

Brener, N. D., Kann, L., Kinchen, S. A., Grunbaum, J. A., Whalen, L., Eaton, D., \& Ross, J. G. (2004). Methodology of the youth risk behavior surveillance system. Morbidity and Mortality Weekly Report, 53, 1-13.

Cesnaitiene, V., Skurvydas, A., Mamkus, G., Juodzbalienè, V., Mickevicienè, D., \& Kavaliauskiene, E. (2010). Influence of visual feedback to accuracy and variability of foot flexion and extension output of women of different age. Education, Physical Training, Sport, 77, 5-11.

Clarkson, P. M., \& Hubal, M. J. (2002). Exercise-induced muscle damage in humans. American Journal of Physical Medicine and Rehabilitation, 8, 52-69.

Department of Health (1997). The new NHS: Modern and dependable. London: The Stationery Office. 
Diener, H. C., Dichgans, J., Bruzek, W., \& Selinka, H. (1982). Stabilization of human posture during induced oscillations of the body. Experimental Brain Research, 45, 126-132.

Doherty, T. J. (2003). Invited review: Aging and sarcopenia. Journal of Applied Physiology, 95, 17171727. doi:10.1152/japplphysiol.00347.2003

Engström, L. M. (1991). Exercise adherence in sport for all from youth to adulthood. In P. Oja, R. Telama (Ed.), Sport for all. (pp. 473-483). Amsterdam: Elsevier Science. Fitts, R. H. (2003). Effects of regular exercise training on skeletal muscle contractile function. American Journal of Physical Medicine \& Rehabilitation, 82, 320-333.

Gandevia, S. C. (2001). Spinal and supraspinal factors in human muscle fatigue. Physiological Reviews, 81, 17251789 .

Gregory, J., Lowe, S., Bates, C. J., Prentice, A., Jackson, L. V., Smithers, G., ...Farron, M. (2000). National Diet and Nutrition Survey: Young people aged 4 to 18 years. Volume 1: Report of the diet and nutrition survey. London: TSO.

Grunbaum, J. A., Kann, L., Kinchen, S., Ross, J., Hawkins, J., Lowry, R., ... Collins, J. (2004). Youth risk behavior surveillance-United States, 2003 (Abridged). Journal of School Health, 74, 307-324.

Hirschfeld, H. (2007). Motor control of every day motor tasks: Guidance for neurological rehabilitation. Physiology and Behavior, 92, 161-166. doi:10.1016/j. physbeh.2007.05.018

Jansen, I., \& LeBlanc A. (2010). Systematic review of the health benefits of physical activity and fitness in schoolaged children and youth. International Journal Society of Behavioral Nutrition and Physical Activity, 7, 40. doi: 10.1186/1479-5868-7-40

Kanehisa, H., Yata, H., Ikegawa, S., \& Fukunaga, T. (1995). A cross-sectional study of the size and strength of the lower leg muscles during growth. European Journal of Applied Physiology and Occupational Physiology, 72, 150-156.

Katayama, Y., Senda, M., Hamada, M., Kataoka, M., Shintani, M. \& Inoue, H. (2004). Relationship between postural balance and knee and toe muscle power in young women. Acta Medica Okayama, 58, 189-195.

Latash, M. L. (2008). Neurophysiological basis of movement (2nd ed.). Champaign, IL: Human Kinetics.

Malina, R. M. (2001). Physical activity and fitness: Pathways from childhood to adulthood. American Journal of Human Biology, 13, 162-172.

Rimmer, J. H, Schiller, W., \& Chen, M. D. (2012). Effects of disability-associated low energy expenditure deconditioning syndrome. Exercise and Sport Science, 40, 2-29. doi:10.1097/JES.0B013E31823B8B82

Skurvydas, A., Brazaitis, M., Kamandulis, S., \& Sipaviciene, S. (2010). Peripheral and central fatigue after muscle damaging exercise is muscle length dependent and inversely related. Journal of Electromyography \& Kinesiology, 20, 655-660. doi: 10.1016/j.jelekin.2010.02.009 Skurvydas, A., Brazaitis, M., Venckunas, T., \& Kamandulis, S. (2011 a). Predictive value of strength loss as an indicator of muscle damage across multiple drop jumps. Applied Physiology, Nutrition, and Metabolism, 36, 353-360. doi: 10.1139/h11-023

Skurvydas, A., Brazaitis, M., Venckūnas, T., Kamandulis, S., Stanislovaitis, A. \& Zuoza A. (2011b). The effect of sports specialization on musculus quadriceps function after exercise-induced muscle damage. Applied Physiology, Nutrition, and Metabolism, 36, 873-880. doi: 10.1139/ h11-112

Stackhouse, S. K., Binder-Macleod, S. A., \& Lee, S. C. (2005). Voluntary muscle activation, contractile properties and fatigability in children with and without cerebral palsy. Muscle and Nerve, 31, 594-601.

Stone, M. H., Stone, M., \& Sands, W. A. (2007). Principles and Practice of Resistance Training. Champaign, IL: Human Kinetics.

Streckis, V., Skurvydas, A., \& Ratkevicius, A. (2007). Children are more susceptible to central fatigue than adults. Muscle and Nerve, 36, 357-363.

Streckis, V., Skurvydas, A., \& Ratkevicius, A. (2005). Twelve- to thirteen-year-old boys are more resistant to low-frequency fatigue than young men. Pediatric Exercise Science, 17, 399-416.

Tammelin, T., Näyhä, S., Hills, A. P., \& Järvelin, M. R. (2003). Adolescent participation in sports and adult physical activity. American Journal of Preventive Medicine, 24, 22-28.

Telama, R., Yang, X., Laakso, L., \& Viikari, J. (1997). Physical activity in childhood and adolescence as predictor of physical activity in young adulthood. American Journal of Preventive Medicine, 13, 317-323.

Telama, R., Yang, X., Viikari, J., Valimaki, I., Wanne, O., \& Raitakari O.T. (2005). Tracking physical activity from childhood to adulthood: A 21-year follow up study. American Journal of Preventive Medicine, 28, 267-273.

U.S. Department of Health and Human Services. (1996). Physical activity and health: A report of the surgeon general. Atlanta, GA: U.S. Department of Health and Human Services, Centers for Disease Control and Prevention, National Center for Chronic Disease Prevention and Health Promotion. Retrieved from http:// www.healthcare.gov/center/councils/nphpphc.

Westerståhl, M., Barnekow-Bergkvist, M., \& Jansson, E. (2005). Low physical activity among adolescents in practical education. Scandinavian Journal of Medicine and Science in Sports, 15, 287-297.

World Health Organization. (2010). Global recommendations on physical activity for health. Switzerland. Retrieved from http://www.who.int/dietphysicalactivity/ factsheet_recommendations/en/ 